\title{
Training in interventional pulmonology: the European and US perspective
}

\author{
Hans J. Lee ${ }^{1}$ and Lorenzo Corbetta ${ }^{2}$
Number 7 in the Series "Interventional pulmonology" Edited by David Feller-Kopman and Hervé Dutau

\begin{abstract}
${ }^{1}$ Division Pulmonary/Critical Care Medicine, Section of Interventional Pulmonology, Johns Hopkins University, Baltimore, MD, USA ${ }^{2}$ Department of Experimental and Clinical Medicine, Interventional Pulmonology Unit, University of Florence, Careggi Hospital, Florence, Italy.
\end{abstract}

Corresponding author: Hans J. Lee (hlee171@jhmi.edu)

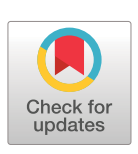

Copyright @ERS 2021

This version is distributed under the terms of the Creative Commons Attribution Non-Commercial Licence 4.0. For commercial reproduction rights and permissions contact permissions@ersnet.org

Received: 28 Jan 2020 Accepted: 12 Oct 2020

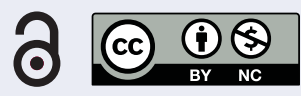

Shareable abstract (@ERSpublications)

While interventional pulmonology is a single specialty, the approach to training varies according to location (Europe and USA). While European and US interventional pulmonology training share similar goals, their pathways and challenges are different. https://bit.ly/34jTyMH

Cite this article as: Lee HJ, Corbetta L. Training in interventional pulmonology: the European and US perspective. Eur Respir Rev 2021; 30: 200025 [DOI: 10.1183/16000617.0025-2020].

\section{Abstract}

As the breadth of interventional pulmonology continues to expand, training in this discipline gains further importance. Interventional pulmonology training in the USA and Europe has common roots and similar concepts; however, there are variations in its delivery. We discuss the similarities, differences, challenges and goals of interventional pulmonology training in both continents. Collaboration and exchange of experiences between the USA and Europe are fundamental to entering the new era of competency/mastery training to implement a multidimensional approach to procedure-related education.

\section{Introduction}

Interventional pulmonology is an emerging subspecialty of pulmonary medicine. Training focuses on the diagnosis and management of central airway obstruction, lung cancer and pleural diseases, and specialised procedural training in various airway and pleural procedures. As a result of growth in technology and increasing patient complexity, the field of interventional pulmonology has expanded to diagnose and treat a wide range of pulmonary diseases. While interventional pulmonology is a single specialty, the approach to training physicians varies according to location (Europe and USA) and has changed over time.

Formal surgical and procedural training in the USA is credited to William Halstead of Johns Hopkins University (Baltimore, MD, USA) at the turn of the 20th century for developing the first US surgical residency training programme. Much of the approach to surgical training was a replication of Halstead's training experience in Europe [1]. While revolutionary at its time, the Halstedian philosophy of "see one, do one, teach one" has evolved in medical education into a multidimensional approach. We will discuss the current and potentially ideal future of interventional pulmonology training on both continents.

\section{Conventional bronchoscopy}

Basic or conventional bronchoscopy is learnt in both North America and Europe during a formal pulmonary fellowship programme with wide heterogeneity. The requirements for flexible bronchoscopy by different credentialing bodies require 100 flexible bronchoscopies in the USA and at least 50 procedures under direct supervision and 50 under indirect supervision in most European countries by the end of the pulmonary fellowship [2]. Volume requirements for conventional bronchoscopy and other more complex procedures are shown in table 1. However, the actual learning curve for single procedures are poorly understood and likely highly variable as training environments/instructors are heterogeneous [3]. 
TABLE 1 Procedural volume requirements in USA and Europe for interventional pulmonology training

\begin{tabular}{lcc} 
& USA & Europe \\
\hline Rigid bronchoscopy & 50 & 20 \\
Endobronchial stenting & 20 & 10 \\
\hline Thoracoscopy & 20 & 10 \\
Bronchoscopic navigation & 20 & 20 \\
Endobronchial ablation & 50 & 20 \\
\hline Endobronchial ultrasound & 100 & 50 \\
\hline Image-guided thoracostomy tube placement & 20 & 10 \\
\hline Tunnelled pleural catheter placement & 20 & 20 \\
Percutaneous dilational tracheostomy & 20 & \\
\hline Percutaneous endoscopic gastrostomy & 20 & 20 \\
Bronchial thermoplasty & 6 & 10 \\
\hline Endobronchial management of bronchopleural fistula & 5 & 10 \\
\hline Endoscopic ultrasound & 30 & 150 \\
\hline Transtracheal oxygen catheter & 5 & $22-38$ \\
\hline Image-guided percutaneous needle biopsy & 5 & \\
\hline Cryobiopsy & & \\
\hline Thoracic ultrasound & & \\
Double lumen tube positioning & & \\
\hline
\end{tabular}

One fundamental approach to this is that the trainees can develop their own logbook, documenting all participating cases which ideally would include pictures/video for recall and reflection, results and outcome. This would allow metrics to be developed and performance quality monitoring, and provide specific feedback tailored to each trainee. In addition, this would be a stronger alternative to the current norm of surrogate markers such as a single point in time feedback and volume requirements. While there are numerous published results on the outcomes of diagnostic procedures, such as transbronchial lung biopsy by clinical researchers, individual physician outcome assessment should be done for their individual diagnostic yield and complications. This would allow for an honest conversation with patients during informed consent and allow physicians to monitor their progress or stagnation. In addition, it would allow individuals to evaluate the usefulness of potentially additive services or technology like rapid on-site evaluation or navigational bronchoscopy.

While there are numerous published qualitative and quantitative assessment tools, many programmes use a global assessment of the fellows' abilities [4]. There are published studies that indicate the lack of reaching competency in basic bronchoscopy procedures by their programme directors [5-7]. This in turn makes the discussion of interventional pulmonology training complex due to heterogeneity in baseline fundamental procedural skills. Despite this, some pulmonary fellowships offer advanced training during fellowships, primarily in the field of advanced diagnostic (i.e. endobronchial ultrasound (EBUS), electromagnetic navigation bronchoscopy, pleural ultrasound) procedures. However, these advanced procedures are not required for many general pulmonary fellowships. With a fixed time for training and an increasing number of procedures, pulmonary fellowship procedural training has become arguably even more deficient. This is reflected in a limited examination of general pulmonologists' lower skill sets [8, 9].

Applying modern principles of adult learning may help optimise limited training time and would suggest that the ideal approach for pulmonary procedural training would include: 1) a developed curriculum; 2) a standardised process for learning; and 3) utilisation of validated assessment tools [10]. According to the more recent didactic methodologies, training in interventional pulmonology can be organised into five stages. 1) A theoretical stage with the use of more interactive teaching methods, such as flipped classroom, problem-based learning, live streaming, e-learning and blended learning (table 2). 2) A practical stage using low-/high-fidelity simulators (role play, artificial models, animal models, virtual reality and practical sessions on cadavers). 3) A practical stage on patients under supervision of a tutor, based on the specific learning curve associated with each procedure and on the individual trainee's predisposition. 4) Quantitative and qualitative assessment of acquired competence and final certification. 5) Life-long learning: continuing professional development is perhaps the most important part of training programmes as it spans the longest time of a physician's career. Enabling physicians to constantly update and improve their professional competence over a career has not been well addressed in our specialty.

Every stage of the learning process can and should be monitored according to specific evaluation metrics (knowledge and skills-based assessment). 


\begin{tabular}{|c|c|}
\hline Initial evaluation & Procedural strategies \\
\hline $\begin{array}{l}\text { Physical examination, complementary tests and } \\
\text { functional status assessment }\end{array}$ & Indications, contraindications and expected results \\
\hline Patient's significant comorbidities & Operator and team experience and expertise \\
\hline Patient's support system (also includes family) & Risk-benefits analysis and therapeutic alternatives \\
\hline $\begin{array}{l}\text { Patient preferences and expectations (also includes } \\
\text { family) }\end{array}$ & Respect for persons (informed consent) \\
\hline Procedural techniques and results & Long-term management plan \\
\hline Anaesthesia and other perioperative care & Outcome assessment \\
\hline Techniques and instrumentation & Follow-up tests, visits and procedures \\
\hline Anatomical dangers and other risks & $\begin{array}{l}\text { Referrals to medical, surgical or palliative/ } \\
\text { end-of-life subspeciality care }\end{array}$ \\
\hline Results and procedure-related complications & $\begin{array}{l}\text { Quality improvement and team evaluation of } \\
\text { clinical encounter }\end{array}$ \\
\hline
\end{tabular}

There are several published studies examining the use of simulators and different curriculums for basic bronchoscopy training [3]. Current specialty societies already recommend the use of simulators and validated summative assessment tools [11-13]. For practical training the following simulator models are available: 1) mannequins and plastic models for endoscopy simulation in order to learn and improve trainees' coordination with the possibility of using video tutoring systems and the most recent type of disposable bronchoscopes; 2) animal models in vivo or single organs, e.g. fresh or frozen porcine lungs, or preserved under plastic lamination (a chest cavity simulator connected to a negative pressure can also be useful, i.e. ArtiCHEST ${ }^{\circledR}$ trainer, custom-made cages); and 3) virtual reality simulation in order to learn the anatomy, to enhance manual dexterity in bronchoscopy and tissue sampling techniques in simulated clinical cases (e.g. BRONCH Mentor, ORSIM ${ }^{\circledR}$, EndoVR ${ }^{\mathrm{TM}}$ ), is also available. However, there are no policies to enforce utilisation of any single method in basic pulmonary procedural training [14].

\section{Interventional pulmonary procedural training}

\section{Structure}

Historically, early US interventional pulmonology physicians relied on travelling to Europe and/or disjointed training from various other specialists such as thoracic surgeons [15]. Training opportunities were extremely rare and required self-sacrifice/initiative. Specialised centres in Europe offered expertise and training in procedures such as rigid bronchoscopy, stenting and medical thoracoscopy, which offered foreign physicians a learning opportunity. Today, many of these European centres continue to offer procedure-specific training and patient care.

The key difference between interventional pulmonology training on both continents is a standardised comprehensive model in North America compared to a shorter procedure-specific model in Europe. Currently over 38 US interventional pulmonology fellowship programmes span 12 months. While funding challenges exist on both continents, the North American fellowship programmes have seen a tremendous growth over the past decade (figure 1) and continue on the pathway for eventual government funding and Accreditation Council of Graduate Medical Education adoption [16, 17]. In 2012, interventional pulmonology was recognised and joined the National Residency Match Programme, which standardised the application process for interventional pulmonology fellowship training in the USA and started the standardisation of interventional pulmonology training [18]. There are several professional societies that have been advocating for formalised interventional pulmonology training in North America: American Association of Bronchology and Interventional Pulmonology (AABIP); Association of Interventional Pulmonary Fellowship Directors (AIPPD); American Thoracic Society (ATS); Association of Pulmonary and Critical Care Medicine Programme Directors; and American College Chest Physicians (ACCP). More recently, all of these societies have developed joint comprehensive accreditation guidelines for interventional pulmonology fellowship training in the USA. The document recommends institutional faculty requirements and policy, curriculum and comprehensive procedural requirements [19].

In Europe, accreditation for interventional pulmonology training follows individual procedures rather than the comprehensive model in the USA, which is shorter in duration with possibly different curriculums. This, in part, stems from Europe consisting of numerous countries with different government regulatory healthcare agencies, thus training in one country may not be recognised in others. However, the European Respiratory Society (ERS) has a certification for EBUS and Thoracic Ultrasound that is widely recognised. The ERS EBUS certification programme was introduced in 2016 and provides professional certification of 
a)

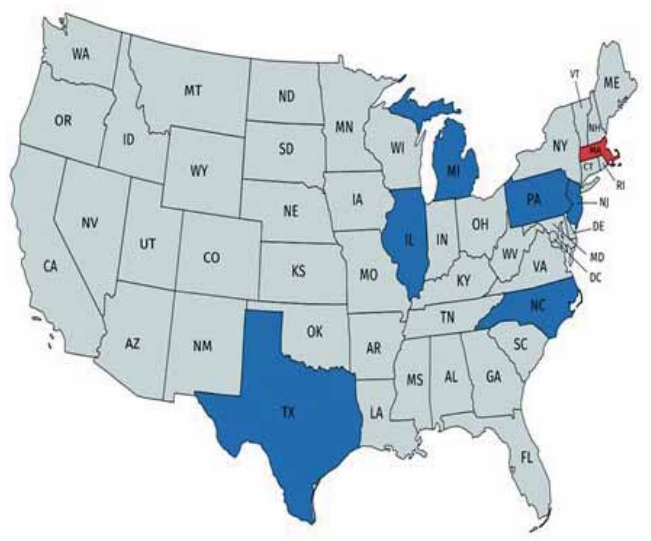

b)

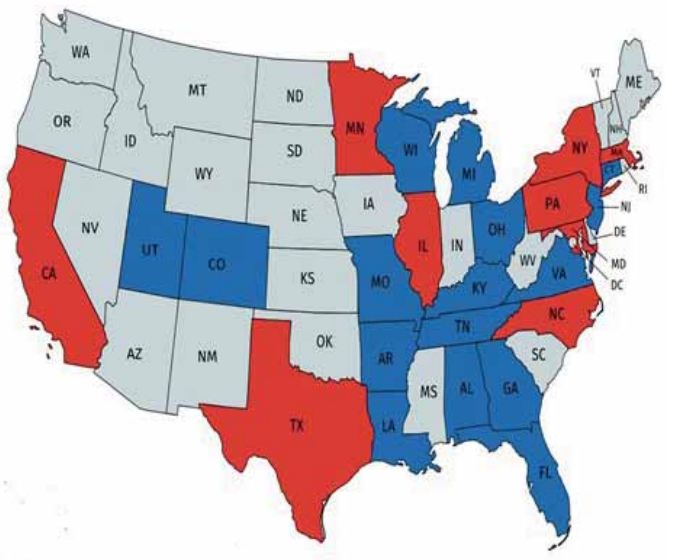

Single programme $\square$ Multiple programmes

\section{ipipipi}

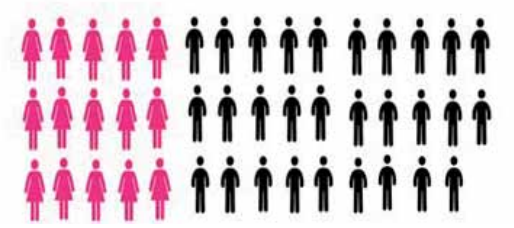

FIGURE 1 Growth of North American interventional pulmonary fellowship programmes in a) 2010 and b) 2020.

competence [20]. This three-part certification training programme consists of didactic (theory) knowledge, clinical and simulation training, and supervised training (figure 2). It follows a blended learning format with a mixture of online, simulation and direct observation. The ERS has set standard procedural requirements and a formal assessment process for certification. There have also been published
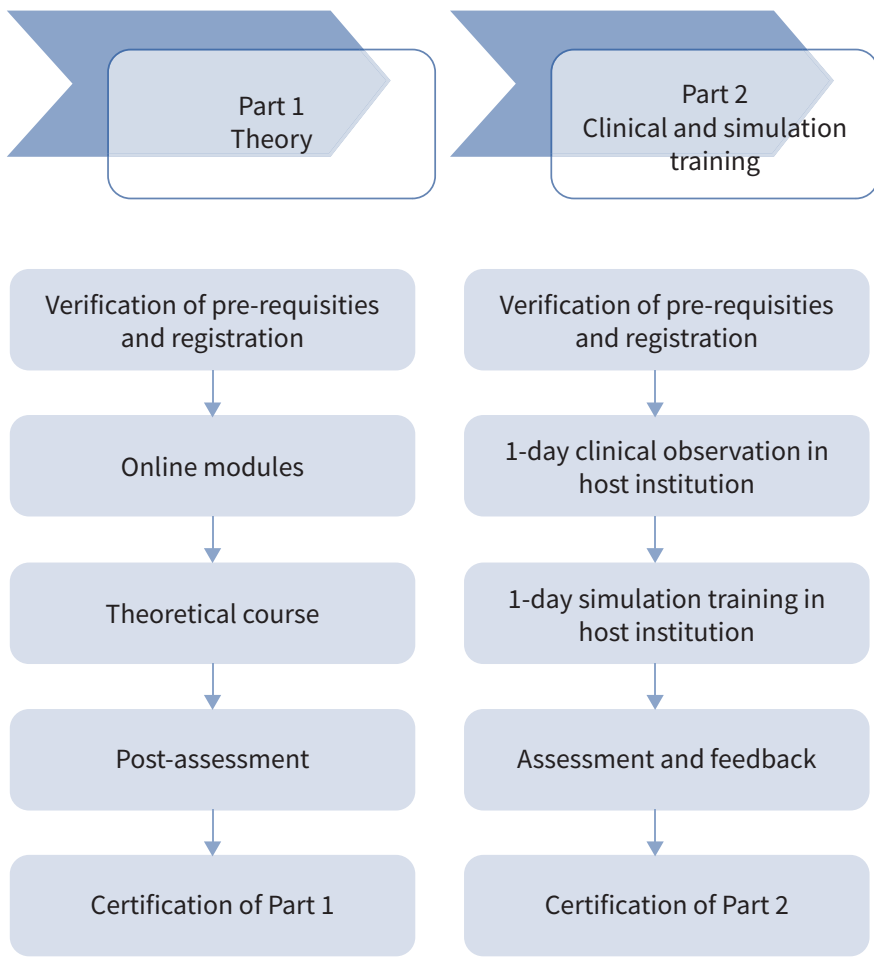

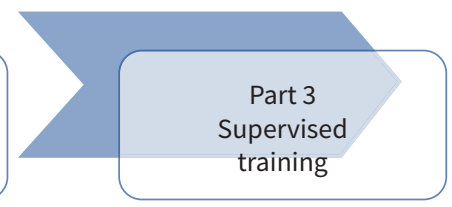

Verification of pre-requisities and registration

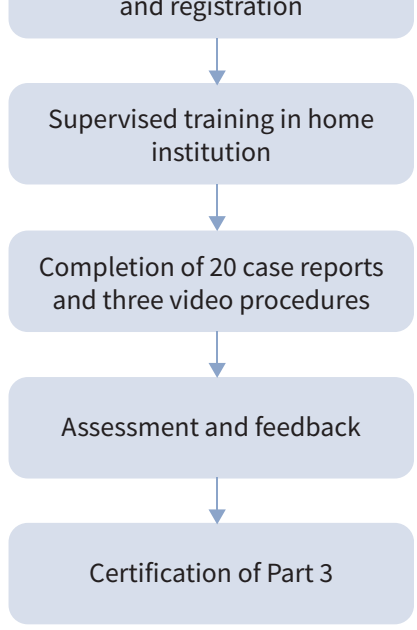

FIGURE 2 European Respiratory Society Endobronchial Ultrasound Training Programme [20]. 
recommendations for competency training of individual interventional pulmonology procedures from European authors [11]. The ERS also organises short courses which are useful for starting interventional pulmonology training or updating on specific topics (i.e. ERS courses).

The ATS/ACCP/ERS have issued a consensus document on measuring competency based on number of procedures performed, which has been challenged by some that additional requirements would be needed and should include the integration of knowledge, skills, values and attitudes (competency-based medical education) [21, 22].

In Europe, individual countries also hold competence-oriented courses and a structured Masters programme, where a diploma is obtained, e.g. 1-year programme in Italy (University of Florence and Ancona) or 2-year programme in France. In Germany, trainees receive interventional pulmonology training in the endoscopy unit for 12 months in tertiary care centres using simulators for the first few weeks with close supervised hands-on training. In the UK, trainees maintain a logbook for 5 years, to be reviewed and signed off periodically by their supervisors. Currently there is not a single common curriculum throughout Europe, nor is a certificate of competence in interventional pulmonology mandatory in Europe, while a diploma is often required when applying for a post. In Italy, a need was determined to standardise interventional pulmonology training programmes, for the 1-year Masters programme as well as the life-long training programme. This would allow trainees to gradually achieve full competence in the majority of interventional pulmonology skills. As the numbers of procedures required to achieve competence is beyond the capability of any single centre, cooperation between hospitals and university centres allowed the programmes to train professional interventional pulmonology physicians by pooling resources in a more structured and effective manner. Certified hospital centres have the knowledge base, skills, attitudes, cases and series of patients, while university centres have the teaching approach, the research focus and the institutional task of certifying competence. Following the model of airline pilot training, every practitioner maintains their own logbook (http://act.pneumologia-interventistica.it), the equivalent of a pilot's flight book or log, where every individual procedure is recorded, every training course attended and intermediate/final assessments of their Master's programme through their professional career are also recorded. In 2015, this programme was standardised at the university post-fellowship training level. A consensus conference was held in Italy to propose a core curriculum for interventional pulmonology training and Master's programme. The curriculum was supported by the European Association for Bronchoscopy and Interventional Pulmonology. The intention was to standardise minimum requirements for interventional pulmonology fellowship programmes and life-long learning, and to offer guiding principles that can be followed on an elective basis, not as a strictly binding standard. This document includes a core curriculum and innovative training methods simulation, and introduces a series of articles describing the knowledge, skills and attitudes required for each specific competency. It also includes recommended teaching methods to be adopted, useful information references and the most appropriate qualitative/quantitative methods for the assessment of competence in each procedure [23].

Both US and European interventional pulmonology training strive for the goal of expertise/mastery through competency-based training in a multitude of disease processes and their associated procedures. Competency-based training programmes have their roots in manufacturing, as industry was researching methods to teach specific knowledge and skills to make products in a standardised manner. This had progressed and was adopted into education as competency-based medical education (CBME), which recognises that not all trainees will master the skills at the same pace and metrics are needed to demonstrate progression to different levels of competency with mastery as its ultimate goal.

Deliberate practice pairs well with interventional pulmonology, CBME and simulation because its applications have been dominated by skilled performance (musicians, athletes and surgeons) [24]. The critical component of deliberate practice is the coach who continues to assess and give immediate feedback with expectation slightly outside of the learner's current abilities. The trainee must trust in their instructors feedback and give effort for improvement. It has often been described as uncomfortable training by educational experts as it has high demands with no immediate rewards [23, 25]. However, the process of training to allow all learners to reach mastery with an expert coach has been found to have consistently positive outcomes in a wide array of disciplines (music, chess, military and athletics) [26]. There have been very few studies examining the differences between additional training in interventional pulmonology compared to self-learning; however, two studies have suggested a cognitive difference between additional interventional pulmonology training compared to self-learning for EBUS and interventional pulmonology didactics [7, 8]. This has been a strong argument for additional fellowship training in US interventional pulmonology and for proctored instruction in Europe.

The Bronchoscopy Education Project (www.bronchoscopy.org) provides training in fundamentals of flexible bronchoscopy. The goal is to build a common level of excellence across national borders. They 
use models, simulation, role play, case-based learning exercises and objective measures of competence (using assessment tools and checklists) to improve technical skills, knowledge and decision making. Available collections of checklists and user instructions include: moderate sedation; fluoroscopy; informed consent; procedural pause and patient safety; practical approach; bronchoscopy step-by-step; proctored bronchoscopy; international flexible bronchoscopy programme completion; and train the trainer courses. It is important to keep in mind that these fundamentals are a starting point to reach a mid-point of competency. However, the goal of reaching expertise/mastery may take a decade of committed training.

\section{Simulation}

A discussion of surgical and procedural training will undoubtedly include the topic of simulation training. The number of different procedures that all trainees need to become competent is vast and increasing. This poses a potential risk to patients involved in the practical stage of interventional pulmonology training. In recent years, a more complex and multi-faceted approach has come into use, centred on the notion "see one, simulate many, do one competently” [27, 28]. Complications are likely to increase with learning any new procedure, including procedures which have a historically low complication rate such as bronchoscopy [29]. This could potentially be avoided by starting with simulation training and then transitioning to clinical care. Even a short simulation session of 1 hour could make an impact on novice bronchoscopic performance [30]. This has led to the development of simulation tools capable of enhancing and facilitating practical hands-on learning, as well as extending the opportunity of training to more students.

Simulation training in interventional pulmonology also offers the opportunity for deliberate practice to gain expertise and train for rare situations (e.g. massive haemoptysis) in a zero-risk environment. However, simulators alone do not create an educational opportunity and must be paired with faculty skilled in simulation which perhaps does not receive enough emphasis compared to the simulator hardware. In fact, most interventional pulmonology procedures do not have a commercial simulator and some centres in the USA/ Europe do not have ready accessibility to relevant simulation centres [22]. While low-fidelity simulators are comparable to the more expensive high-fidelity simulators for basic bronchoscopy competency, this may not be the case for mastery skills and is unknown for more sophisticated procedures such as robotic procedures [31].

Simulation on animal models in vivo or on individual organs, such as for example pig lungs, either frozen or preserved under plastic lamination, may be another useful option in all endoscopy procedures. While there are fewer studies than for other simulators, it may offer realism; however, there is variability on access and cost depending on the country in practice. Many institutions have used animal models for airway management courses, bronchoscopy continuing medical education courses (for EBUS and interventional pulmonology techniques), and during pulmonary and interventional pulmonology fellowship training. Advantages of wet lab models over computer models include increased realism (i.e. soft tissue texture) and giving the learners the opportunity to use actual bronchoscopy equipment. Disadvantages of the wet lab models are the ethical issues associated with the use of animals for research and education, the cost of the highly trained personnel required to ensure safe and humane handling of the animals, and the cost associated with dedicated animal bronchoscopy equipment. There are no publications comparing wet lab simulation with high-fidelity and low-fidelity simulation for bronchoscopy training. There is a need to evaluate the cost/benefit ratio and compliance with national legislation.

The use of embalmed human or animal cadavers in the teaching of bronchoscopy has been well documented, and the exercises have been studied by RAm et al. [32] who have shown that they allow trainees to develop the psychomotor skills needed to perform a bronchoscopy correctly. However, the use of cadaver models does present considerable limitations, essentially in that they are incapable of reproducing the exact situation or the complications of a living being, such as the movements of the cardiorespiratory system, coughing, muscle spasm and haemorrhage. Furthermore, depending on the location, the donor may have been required to have given their consent when still alive, and the procedure on cadaver material can only be performed in specifically authorised centres [33, 34].

Several instructional design key features have been described for simulation-based education (table 3) [35].

A future need in both North America and Europe for interventional pulmonology training will be the development of accessibility to relevant training simulators, trained faculty and educational strategies. Since most new devices are developed for interventional pulmonology in the USA and Europe, the interventional pulmonology community should press industry to include comprehensive training models when introducing their new technology. 
TABLE 3 Instructional design key features for simulation-based education

\begin{tabular}{lc} 
Repetitive practice & Outcome metrics \\
Distributed practice & Knowledge \\
Range of difficulty & Subjective skills \\
Cognitive interactivity & Objective skill assessment \\
Mastery learning & Patient outcomes such as complications, procedural time, etc. \\
Individualised learning & \\
Feedback & \\
Clinical variation & \\
\hline
\end{tabular}

Assessment

Procedural training in general requires cognitive and psychomotor skills. Cognitive skills can be divided into an understanding of the disease process and decision-making. The cognitive aspects of procedural training may be measured in numerous fashions including recall and decision-making scenarios on multiple-choice question examinations (MCQE). There are validated MCQE used for interventional pulmonology including the US interventional pulmonology fellowship in-service examination and AABIP board examination [7]. The ERS has also established two programmes. 1) HERMES (Harmonising Education in Respiratory Medicine for European Specialists), consisting of a yearly multiple-choice questionnaire covering all areas of pulmonology including flexible bronchoscopy, difficult intubation and insertion of a chest drain. Optional competencies are those related to certain interventional procedures, such as transbronchial biopsy, autofluorescence bronchoscopy, rigid bronchoscopy and therapeutic procedures (e.g. laser, prosthesis, etc.). 2) A programme providing professional certification of competence in bronchoscopy with EBUS, which was introduced in 2016. The aim of this project is to train qualified physicians so that they are able to perform EBUS independently and competently. This training project will ensure that participants possess all the necessary knowledge and skills required to obtain ERS certification in EBUS. In this training project assessment includes either a live or video recording of sample procedures for evaluation. This offers the benefit of a summative evaluation beyond MCQE where psychomotor skills can be evaluated by an unbiased committee.

The most defining assessment of cognitive knowledge for US interventional pulmonology physicians is the AABIP-sponsored interventional pulmonology board examination. This examination defines a US interventional pulmonology physician through passing a high-stakes computed-based MCQE which is developed in conjunction with content experts, educators and psychometric specialists. The examination is computer based, which allows for image-based questions as well, and is time limited. Currently, eligibility for this examination can only come through completing an AABIP/AIPPD accredited interventional pulmonology fellowship programme. While MCQE is the standard for medicine-based specialties in the USA, it lacks evaluation of communication and psychomotor skills.

Assessment/feedback is an essential part of the cycle to accomplish procedural mastery. When learners fail to demonstrate improvement, they are ideally given immediate feedback in specific areas to practice and are then tested again. This cycle continues until the learner accomplishes competency then mastery prior to undertaking a more complex skill task. In interventional pulmonology, we lack formative assessment tools to aid in the feedback and setting standards; however, there are ongoing development projects in this field, and recently standards for certain procedures have been developed [36-38]. In addition, we need faculty development to optimise pedagogical methods in developing/assessing decision-making, psychomotor skills and medical knowledge.

An objective evaluation of a practitioner's skills can be done through Direct Observation of Procedural Skills (DOPS). Two instruments were studied and validated for the assessment of basic bronchoscopy skills: the Bronchoscopy Skills and Tasks Assessment Tool and the Bronchoscopy Stepwise Evaluation Tool.

For more complex procedures, the following DOPS have been validated respectively by US and European Centres.

1) EBUS Skill Assessment Tool: this is a 10-section assessment tool incorporating anatomy, equipment handling, and computed tomography and EBUS image interpretation [39].

2) EBUS Assessment Tool: the tool was designed according to the original format for "objective structured assessment of technical skills", in which each item is rated on a scale from 1 to 5, with descriptive anchors in the middle and at the ends, and re-coded into a score from 0 to 4 points. Six items were designed to 
assess knowledge of the mediastinal anatomy, by requesting the operators to identify six anatomical landmark lymph node stations $(4 \mathrm{~L}, 7,10 \mathrm{~L}$ or $11 \mathrm{~L}, 10 \mathrm{R}$ or $11 \mathrm{R})$, the azygos vein and lymph node station 4R. Four items related to the technical skills necessary to handle the scope and perform transbronchial needle aspiration were defined: insertion of the endoscope, positioning of the transducer, use of sheath and use of needle. Finally, two items were added to allow assessors to give their overall opinion on anatomical orientation and biopsy sampling [40]. An Endoscopic Ultrasonography Assessment Tool for endoscopic ultrasound fine-needle aspiration mediastinal staging is also available [41]. The Ultrasound-Guided Thoracentesis Skills and Tasks Assessment Test was devised, following the guidelines of the British Thoracic Society, as a tool to evaluate the teaching of thoracic ultrasound before clinical practice. It consists of a questionnaire with a score on a scale of 100 , which can be administered to learners with different levels of experience in thoracic ultrasound procedures, from beginners to intermediate levels and even to advanced level thoracic ultrasound practitioners [42].

The AABIP Certificate of Advanced Qualification is a new examination for practising interventional pulmonologists that may focus on more common but not all interventional pulmonology procedures. It has the following features: 1) a Knowledge Assessment Test; 2) a computer-based Knowledge Assessment Test; 3) utilises clinical vignettes and a multiple-choice questions-based format similar to other US board certification examinations; 4) procedure logs and the Procedural Skills Assessment Test (PAT) will be used in lieu of the formal training requirements for Interventional Pulmonology Board Certification; 5) multiple test sites around the country will offer the PAT at different times throughout the year to provide flexibility for the candidates; and 6) a detailed step-by-step preparation guide will be released to help candidates prepare for the PAT.

The assessment of competent and expert physicians is often challenging when using some of the above-mentioned checklists due to experts often skipping steps or where they have innovated new techniques for the procedure. For this reason, some educators have used a global rating scale which is more of an overall scaled assessment (i.e. poor, adequate, excellent). The global rating scale, when compared with checklists, is more sensitive in assessing competency but may not offer formative feedback to the learner or researcher [43].

\section{Post-fellowship interventional pulmonology training}

Developing new procedural skills after formal fellowship training is becoming more important as the procedural training during fellowships probably will not last an entire career, and new skill sets will be required shortly after formal training. Additionally, many physicians will hit a plateau in their procedural skill level after training, which represents the "competency" marker, or what some educators have labelled “arrested development” [9]. Physicians may fail to progress from competent to expertise or mastery without additional training. However, the opportunities for training after fellowship are challenging on both continents. Instruction on life-long learning during training should be stressed to avoid arrested development. Continuing medical education or professional development is often in the form of a 1- to 3-day course/ conference and observership at other hospitals. This may be more practical in Europe due to existing partnerships (European Union), closer geographical opportunities and the established system for individual procedural training. Practice centres or boot camps, where training takes place through a gradual process from theory to practice, using live sessions and simulation may provide a training approach that is more in harmony with current needs to improve competence and continuous professional development [44]. Some European models of a multidisciplinary boot camp in Europe include the IRCAD (Research Institute against Digestive Cancer) in Strasbourg, France, and the JMC Simulation Unit (Copenhagen, Denmark; www.rigshospitalet.dk/english/contact-us/Pages/default.aspx) [45].

In the USA, hands-on training in different hospitals is difficult due to the stringent licensing and regulations. Video recordings and review by experts with specific feedback may be a potential solution to receive peer coaching after formal training. This model of community learning is currently being used in robotic surgery training by utilising video-based peer feedback through social networking [46]. While mastery learning is the next level after competency, our resources do not easily support this critical goal, leaving many physicians in a state of arrested development after training.

\section{Conclusion}

European and US interventional pulmonology training share similar goals but face different challenges. Both will have to continuously innovate a structure for accessible faculty, training curriculum/structures and assessments. Collaboration and exchange of experiences between the USA and Europe are fundamental to entering the new era of competency/mastery training to implement a multidimensional approach to procedure-related education. It is time to combine the two different cultures and approaches to 
interventional pulmonology training in a more pragmatic transmission of consolidated knowledge and competence. Neither language nor geography should be a barrier to sharing science and best practices in the era of global citizenship [47].

Provenance: Commissioned article, peer reviewed.

Previous articles in this series: No. 1: DeMaio A, Sterman D. Bronchoscopic intratumoral therapies for nonsmall cell lung cancer. Eur Respir Rev 2020; 29: 200028. No. 2: Chandrika S, Yarmus L. Recent developments in advanced diagnostic bronchoscopy. Eur Respir Rev 2020; 29: 190184. No. 3: Kniese CM, Musani Al. Bronchoscopic treatment of inoperable nonsmall cell lung cancer. Eur Respir Rev 2020; 29: 200035. No. 4: Rosell A, Stratakos G. Therapeutic bronchoscopy for central airway disease. Eur Respir Rev 2020; 29: 190178. No. 5: Bedawi EO, Guinde J, Rahman NM, et al. Advances in pleural infection and malignancy. Eur Respir Rev 2021; 30: 200002. No. 6: Perotin JM, Dewolf M, Launois C, et al. Bronchoscopic management in asthma, COPD and emphysema. Eur Respir Rev 2021; 30: 200029.

Conflict of interest: H.J. Lee has nothing to disclose. L. Corbetta has nothing to disclose.

\section{References}

1 Cameron JL. William Stewart Halsted. Our surgical heritage. Ann Surg 1997; 225: 445-458.

2 Fielding DI, Maldonado F, Murgu S. Achieving competency in bronchoscopy: challenges and opportunities. Respirology 2014; 19: 472-482.

3 Stather DR, Chee A, Maceachern P, et al. Endobronchial ultrasound learning curve in interventional pulmonary fellows. Respirology 2015; 20: 333-339.

4 Davoudi M, Osann K, Colt HG. Validation of two instruments to assess technical bronchoscopic skill using virtual reality simulation. Respiration 2008; 76: 92-101.

5 Pastis NJ, Nietert PJ, Silvestri GA. Variation in training for interventional pulmonary procedures among US pulmonary/critical care fellowships: a survey of fellowship directors. Chest 2005; 127: 1614-1621.

6 Wong W, Knox D. Graduating fellows' procedural comfort level with pulmonary critical care procedures. J Bronchol Interv Pulmonol 2019; 26: 231-236.

7 Stather DR, Jarand J, Silvestri GA, et al. An evaluation of procedural training in Canadian respirology fellowship programs: program directors' and fellows' perspectives. Can Respir J 330 2009; 16: 55-59.

8 Lee HL, Feller-Kopman D, Shepherd W, et al. Validation of an interventional pulmonary examination. Chest 2013; 143: 1667-1670.

9 Vial MR, O'Connell OJ, Grosu HB, et al. Diagnostic performance of endobronchial ultrasound-guided mediastinal lymph node sampling in early stage non-small cell lung cancer: a prospective study. Respirology 2018; 3: 76-81.

10 Desai NR, Parikih MS, Lee HJ. Interventional pulmonology: the role of simulation and competency-based evaluation. Semin Respir Crit Care Med 2019; 39: 747-754.

11 Ernst A, Wahidi MM, Read CA, et al. Adult bronchoscopy training: current state and suggestions for the future: CHEST Expert Panel Report. Chest 2015; 148: 321-332.

12 Corbetta L, Patelli M. Executive summary of training and competence standards for the Interventional Pulmonology Master Program in Italy. J Bronchol Interv Pulmonol 2018; 25: 6-8.

13 McSparron JI, Michaud GC, Gordan PL, et al. Simulation for skills-based education in pulmonary and critical care medicine. Ann Am Thorac Soc 2015; 12: 579-586.

14 Valentini I, Lazzari Agli L, Michieletto L, et al. Competence in flexible bronchoscopy and basic biopsy technique. Panminerva Med 2019; 61: 232-248.

15 Silvestri G. Looking to our past to find the way forward for the American Association of Bronchology and Interventional Pulmonology. J Bronchol Intervent Pulmonol 2010; 17: 1-2.

16 Bragg EJ, Warshaw GA, Meganathan K, et al. National survey of geriatric medicine fellowship programs: comparing findings in 2006/07 and 2001/02 from the American Geriatric Society and Association of Directors of Geriatric Academic Programs Geriatric Workforce Policy Studies Center. J Am Geriatr Soc 2010; 58: 2166-2172.

17 Strohl KP. Sleep medicine training across the spectrum. Chest 2011; 139: 1221-1231.

18 Lee HJ, Yarmus L. The new NRMP fellowship match system. J Bronchol Intervent Pulmonol 2011; 18: 5-6.

19 Mullon JJ, Burkart KM, Silvestri G, et al. Interventional Pulmonary Fellowships Accreditation Standards: Executive Summary of the Multisociety Interventional Pulmonary Fellowships Accreditation Committee. Chest 2017; 151: 1114-1121.

20 European Respiratory Society. Endobronchial Ultrasound (EBUS) Certified training Programme. https:// www.ersnet.org/education-and-professional-development/ers-certified-training-programmes/endobronchialultrasound-ebus-certified-training-programme/ Date last accessed: June 2020. 
21 Bollinger CT, Mathur PN, Beamis JF, et al. ERS/ATS statement on interventional pulmonology. European Respiratory Society/American Thoracic Society. Eur Respir J 2002; 19: 356-373.

22 Ernest A, Silvestri G, Johnstone D. Interventional pulmonary procedures guidelines from the American College of Chest Physicians. Chest 2003; 123: 1693-1717.

23 Corbetta L, Arru LB, Mereu C, et al. Competence and training in interventional pulmonology. Panminerva Med 2019; 61: 203-231.

24 Rousmaniere T, Goodyear RK, Miller SD, et al. Cycle of Excellence: Using Deliberate Practice to Improve Supervision and Training. Hoboken, NJ, USA, Wiley-Blackwell Publishing, 2017.

25 Taras J, Everett T. Rapid cycle deliberate practice in medical education - a systematic review. Cureus 2017; 9: e1180.

26 Ericsson KA, Charness N, Feltovich PJ, et al. The Cambridge Handbook of Expertise and Expert Performance. Cambridge, UK, Cambridge University Press, 2006.

27 Vozenilek J, Huff JS, Reznek M, et al. See one, do one, teach one: advanced technology in medical education. Acad Emerg Med 2004; 11: 1149-1154.

28 Davoudi M, Colt HG. Bronchoscopy simulation: a brief review. Adv Health Sci Educ Theory Pract 2009; 14 287-296.

29 Ouellette DR. The safety of bronchoscopy in a pulmonary fellowship program. Chest 2006; 130: 1185-1190.

30 Blum MG, Powers TW, Sundaresan S. Bronchoscopy simulator effectively prepares junior residents to competently perform basic clinical bronchoscopy. Ann Thorac Surgery 2004; 78: 287-291.

31 Nilsson PM, Naur TMH, Clementsen PF, et al. Simulation in bronchoscopy: current and future perspectives. Adv Med Educ Pract 2017; 8: 755-760.

32 Ram B, Oluwole M, Blair RL, et al. Surgical simulation: an animal tissue model for training in therapeutic and diagnostic bronchoscopy. J Laryngol Otol 1999; 113: 149-151.

33 Hatton KV, Price S, Raig L. Educating anesthesiology residents to perform percutaneous cricothyrotomy, retrograde intubation and fiberoptic bronchoscopy, using preserved cadavers. Anesth Anal 2006; 103: 1205-1258.

34 Gilbert CR, Yarmus L, Feller-Kopman D. Educating the next generation of pulmonary fellows in transbronchial needle aspiration. Leading the blind to see. Ann Am Thorac Soc 2014; 11: 828-832.

35 Kovacs G. Procedural skills in medicine: linking theory to practice. J Emerg Med 1997; 15: 387-391.

36 Mahmood K, Wahidi M, Osann K, et al. Development of a tool to assess basic competency in the performance of rigid bronchoscopy. Ann Am Thorac Soc 2016; 13: 502-511.

37 Lee HJ, Lerner A, Coleman B, et al. Learning electromagnetic navigational bronchoscopy and percutaneous transthoracic needle biopsy (LEAP): a pilot study. J Bronchol Interv Pulmonol 2019; 26: 55-61.

38 Ishman SL, Brown DJ, Boss EF, et al. Development and pilot testing of an operative competency assessment tool for pediatric direct laryngoscopy and rigid bronchoscopy. Laryngoscope 2010; 120: 2294-2300.

39 Davoudi M, Colt HG, Osann KE, et al. Endobronchial ultrasound skills and tasks assessment tool assessing the validity evidence for a test of endobronchial ultrasound-guided transbronchial needle aspiration operator skill. Am J Respir Crit Care Med 2012; 15: 773-779.

40 Konge L, Clementsen PF, Ringsted C, et al. Simulator training for endobronchial ultrasound: a randomised controlled trial. Eur Respir J 2015; 46: 1140-1149.

41 Konge L, Vilmann P, Clementsen P, et al. Reliable and valid assessment of competence in endoscopic ultrasonography and fine-needle aspiration for mediastinal staging of non-small cell lung cancer. Endoscopy 2012; 44: 928-933.

42 Salamonsen M, McGrath D, Steiler G, et al. A new instrument to assess physician skill at thoracic ultrasound, including pleural effusion markup. Chest 2013; 144: 930-934.

43 Ilgen JS, Ma IW, Hatala R, et al. A systematic review of validity evidence for checklists versus global rating scales in simulation based assessment. Med Educ 2015; 49: 161-173.

44 Nakazato T, Callahan Z, Kuchta K, et al. A 1-day simulation-based boot camp for incoming general surgery residents improves confidence and technical skills. Surgery 2019; 166: 572-579.

45 Konge L, Ringsted C, Bjerrum F, et al. The Simulation Centre at Rigshospitalet, Copenhagen, Denmark. J Surg Educ 2015; 72: 362-365.

46 Carter SC, Chiang A, Shah G, et al. Video-based peer feedback through social networking for robotic surgery simulation: a multicenter randomized controlled trial. Ann Surg 2015; 261: 870-875.

47 Bronchoscopy International. English is the new Latin. https://bronchoscopy.org/english-is-the-new-latin Date last updated: 18 January 2020; date last accessed: June 2020. 